\title{
An Atypical Form of Gliosis Spinalis.-Oppen-
} heim (Archiv. f. Psychiat. u. Nervenkr., xxv., Part ii., p. 315, I 893$)$.

A forty-year-old man taken sick in 1882 with progressive disturbance of vision, lancinating pains and feeling of weakness in the legs, previous diplopia, girdle sensation, sensation of numbness in feet and of cold in the legs, and uncertainty of gait. Later on, incontinence of urine and feces. Hemicrania had existed for a long time. In I884, marked kyphoscoliosis of the thoracic vertebræ. Double optic atrophy, right pupil irresponsive to light, the left responded slightly. Absence of right patellar reflex, left normal. No motor weakness in the extremities, likewise no muscle atrophy. Ataxia and Romberg's symptom extreme. Sensibility of the arms good. On the left hip feeling quite lost, at least complete analgesia and thermo-anæsthesia, while sensation of touch was not entirely gone. A similar disturbance but less marked over left thigh which diminished in passing to the leg and foot. In the right lower extremity sensory disturbance was much less marked, less definite and only in patches. For instance, pain and thermo-anæsthesia on the right side was only apparent around the patella. On the shoulders and around the scrotum the loss of sensation is the same on both sides. Sensation of position well preserved. In June, I890, psychical disturbance-dementia paralytica; death, three months later.

Post-mortem-Pachymeningitis and leptomeningitis cerebralis chronica. Gliomatosis medullæ spinalis et degeneratio grisea funicul, post. Fractura tibiæ et fibulæ dextra.

Microscopically.--The gliosis began in the lower part of the cervical enlargement and extended through the thoracic portion of the cord and as far as the lumbar enlargement. In the cervical portion the gliosis confined itself to the area of the posterior columns and the posterior commissure, in upper thoracic portion it extended itself laterally and posteriorly so that at this level the gliosis involved the posterior columns, the posterior horns, the commissures, and here and there in various sections it extended into part of the anterior horns.

In the middle and lower sections of the thoracic portion of the cord and likewise in the lumbar portion the area of gliosis is more and more confined to the left posterior horn, and thereby Clark's column and the posterior column on the left side seem to be atrophied from the pressure of the diseased area. 
While in the lower thoracic cord the area of gliomatosis involves the left posterior horn and causes atrophy of Clark's column and the posterior columns, on the right side at this level there appears sharply limited to Goll's column a complete degeneration and an accompanying atrophy of the fibres of the medial half of Clark's column. Farther down, that is in the upper lumbar cord, this degeneration of Goll's columns becomes diffuse, especially toward the right posterior root zone and right posterior column.

In the lumbar cord, the gliosis in the left posterior horn is confined to a very small area. The degeneration of the right posterior column is, however, very apparent.

The question which the author puts to himself: Is this a case of tabes dorsalis with syringomyelia, or a special form of gliosis which by its spreading out into the posterior columns has produced the symptoms of tabes?-he does not answer definitely, but leans to the latter supposition.

J. C.

Cortical Localiation of the Movement of the Face.-Brissand. (Le Progres Medical, Dec. 31, I893).

A man, eighty years old, who had for long suffered from myocarditis and a dilated heart secondary to emphysema, was stricken with an apoplectic attack in April, I 889. Loss of consciousness for about an hour, paralysis of the entire right side, and aphasia. Little by little, in the course of a few days, speech returned, the hemiplegia gradually passed away, and finally there was left but slight numbness and clumsiness of the fingers. Two years later, the patient entered the hospital on account of cardiac insufficiency. At this time the symptoms of the previous hemiplegia referable to the right extremity, had about disappeared. The face was absolutely asymetrical, the mouth turned to the left, the left commissure of the mouth open, the right commissure firm, lowered, and allowed a continual dribbling of saliva. The left nostril less prominent, the ala of the nose on this side completely immobile, and the lines of expression are effaced. The right eyelid drooping; meanwhile, it is possible to close it voluntarily, but not so well as the left lid. 'The movements of the eyeball are well preserved, but the pupil of the right eye is greatly dilated, but it reacts to light and distance. The lines on the forehead on the right side are quite effaced, but are very pronounced on the left side of the median line. 